\begin{tabular}{c|c|c}
\hline \hline $\begin{array}{c}\text { Vol. 481: 239-248, 2013 } \\
\text { doi: } 10.3354 / \text { meps10260 }\end{array}$ & $\begin{array}{c}\text { MARINE ECOLOGY PROGRESS SERIES } \\
\text { Mar Ecol Prog Ser }\end{array}$ & Published May 7 \\
\hline \hline
\end{tabular}

\title{
Re-established stony reef attracts harbour porpoises Phocoena phocoena
}

\author{
L. Mikkelsen ${ }^{1,2, *}$, K. N. Mouritsen ${ }^{1}$, K. Dahl ${ }^{2}$, J. Teilmann' ${ }^{2}$, J. Tougaard ${ }^{2}$ \\ ${ }^{1}$ Department of Bioscience, Aarhus University, 8000 Aarhus C, Denmark \\ ${ }^{2}$ Department of Bioscience, Aarhus University, 4000 Roskilde, Denmark
}

\begin{abstract}
Stony reefs in shallow water support abundant and species-rich animal communities, and may thus attract top predators such as the harbour porpoise. In summer 2008, the nature restoration project Blue Reef re-established $45000 \mathrm{~m}^{2}$ of cavernous stony reef at Læsø Trindel in the northern Kattegat, Denmark. To investigate whether the re-established reef attracts harbour porpoises, the acoustic activity of porpoises was monitored by static acoustic data loggers, T-PODs, before and after the restoration project. T-PODs were placed at the Læsø Trindel reef and at a reference station $10 \mathrm{~km}$ away between June and August from 2006 to 2012. Results showed that porpoise activity increased significantly at Læsø Trindel reef after the reconstruction in 2008. The number of minutes with porpoise recordings (PPM) increased on average from 9.5 PPM per day in 2006 to a maximum in 2010 (15.2 PPM per day) followed by a small decrease (12.75 PPM per day in 2012). An increase in mean encounter duration from $3.0 \mathrm{~min}$ in 2006 to $4.7 \mathrm{~min}$ in 2010 (3.7 min in 2012) showed that porpoises not only appeared more often, but also stayed longer at Læsø Trindel. Furthermore, there was a striking diel pattern in porpoise activity at Læsø Trindel, with significantly higher activity during the night. This pattern became increasingly apparent over the study period. At the reference station, in contrast, most activity took place during the day throughout the study. The results suggest that these changes reflect a new food source which occurs at night on the re-established stony reef and is exploited by the porpoises.
\end{abstract}

KEY WORDS: Nature restoration - Habitat selection - Acoustic activity - Timing porpoise detector · T-POD · Passive acoustic monitoring · PAM · Diel pattern · Foraging · Blue Reef · Natura 2000

Resale or republication not permitted without written consent of the publisher

\section{INTRODUCTION}

A cavernous stony reef is an important habitat type that supports a rich diversity of flora and fauna (Ojeda \& Dearborn 1989, Andrulewicz et al. 2004). The stable surface of the boulders is essential as anchorage for numerous species of macroalgae and a large variety of sessile animals. In the upper photic zone, the dense algal forests attract numerous species of freeliving animals which feed and hide among the complex structures made up of stones and associated algal vegetation. In particular, numerous fish species are attracted to such reef habitats, which provide an increased food supply (Moreno \& Jara 1984) and a reduced risk of predation due to the refuge offered by the heterogeneous environment (Demartini \& Roberts 1990). The resulting large aggregation of fish at the reef is also likely to attract top predators, such as the harbour porpoise Phocoena phocoena, in much the same way as for piscivorous fish (Logan Kock 1982, Leitão et al. 2008).

The harbour porpoise is the most common cetacean in the North Sea, the inner Danish waters and the Baltic Sea (Hammond et al. 2002). The distribution and movements of harbour porpoises are believed to be strongly connected to prey abundance. Their comparatively small body size, in combination with the relatively cold environment, necessitates daily 
foraging to meet their basic energy requirements (Koopman 1998). Accordingly, Sveegaard et al. (2012b) showed that the spatial distribution of harbour porpoises in the northern Kattegat and Skagerrak appears to be correlated with the distribution of herring Clupea harengus. Herring is an important prey species for porpoises in this area, together with Atlantic cod Gadus morhua, gobies (Family: Gobiidae) and whiting Merlangius merlangus (Aarefjord et al. 1995, Börjesson et al. 2003, Sveegaard et al. 2012a). Porpoise abundance has also been linked to physical parameters, such as tidal phase, local hydrographic fronts and steep sea-bottom topography in combination with strong currents, as these features often lead to aggregation of prey (Johnston et al. 2005, Goodwin 2008, Pierpoint 2008). However, knowledge of specific foraging strategies and habitat selection of harbour porpoises is still limited.

Stony reefs in Danish shallow waters (2 to $10 \mathrm{~m}$ ) have been intensively exploited for the construction of harbour piers and coastal protection. In 2006, the nature restoration EU LIFE project Blue Reef (www. bluereef.dk) was assigned to re-establish a viable stony reef at Læsø Trindel within a Danish Natura 2000 site (Fig. 1). A baseline investigation (Dahl et al. 2009) showed that after decades of boulder extraction, the height of the reef at Læsø Trindel had been reduced by $3 \mathrm{~m}$ from the top, resulting in a vertical distribution of 4 to $18 \mathrm{~m}$ below sea level). As most of

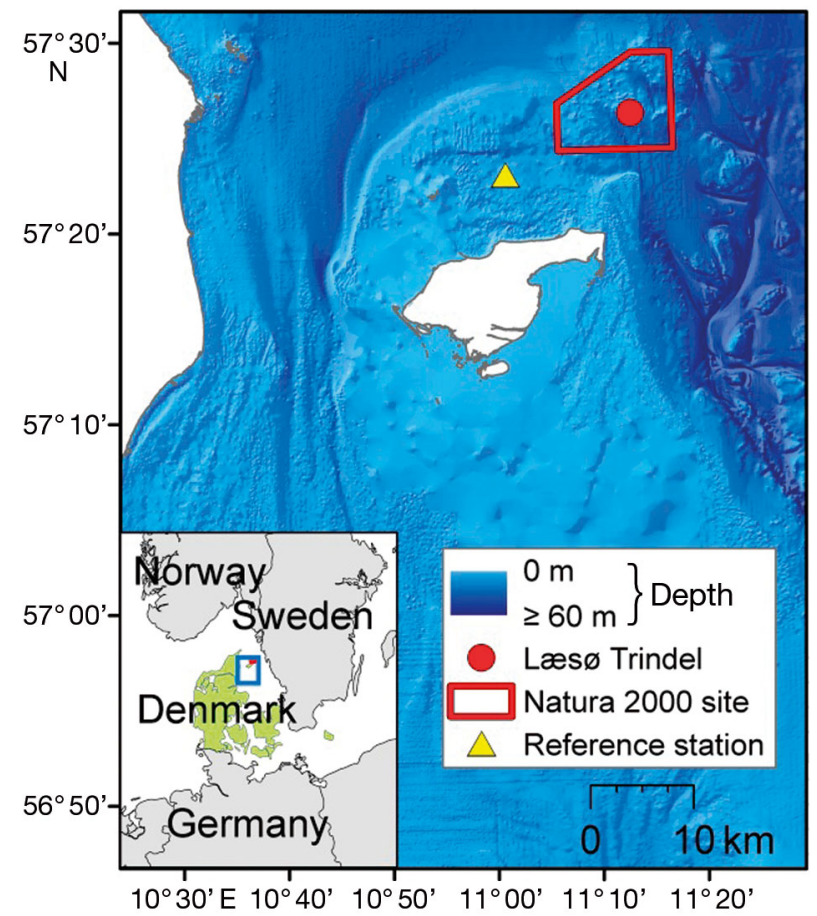

Fig. 1. Study area in the northern Kattegat, Denmark the large boulders had been removed, the reef consisted mostly of sand, gravel and smaller stones, which were very unstable in the shallower parts due to wave action. In some central parts of the reef, a few larger stones were found (up to $1 \mathrm{~m}$ in diameter); however, only a few cavernous structures were present. The algal vegetation at that time was characterised by opportunistic species, resulting in a relatively low biomass of primary producers. Similarly, the biomass of the benthic fauna was small and dominated by bryozoans attached to the laminar of algae and newly settled blue mussels Mytilus edulis. The fish community was also relatively poor and dominated by species of wrasse (Family: Labridae).

The reconstruction focused primarily on (1) mechanically stabilising the reef in an attempt to prevent further erosion; (2) creating cavernous areas of different sizes and depths; and (3) restoring the old vertical distribution of the reef up to 1.5-18.0 m water depth (Fig. 2). Approximately 100000 t of newly broken norite boulders from Norway, weighing between 0.6 and $6.0 \mathrm{t}$, were dumped over $19 \mathrm{~d}$ in the period 13 June 2008 to 11 September 2008. The reconstructed area covers a total of $45000 \mathrm{~m}^{2}$ (Fig. 2). Reconstruction of the reef was expected to result in an increased abundance of plants and animals associated with shallow, stony reef habitats. Particular interest surrounded commercially important species such as Atlantic cod and Atlantic lobster Homarus gammarus. During the expected colonisation period for flora and fauna following the reconstruction (i.e. 2009 to 2012), all fishing activity in the area was prohibited. Previous studies have shown that construction of artificial reefs does indeed result in a wealth of life (Fager 1971, Russell 1975, Bohnsack \& Sutherland 1985). Likewise, several studies have found that artificial reefs are very successful in attracting fish and often support a high secondary production due to the food resources and shelter provided by the reef (Charbonnel et al. 2002, Relini et al. 2002, Giansante et al. 2010).

Based on the presumption that the newly restored reef at Læsø Trindel would increase prey availability, we hypothesised that harbour porpoise abundance would also increase in the years following restoration. Furthermore, we anticipated that this increased abundance would be detectable as increased acoustic activity. Porpoises produce ultrasonic pulses with a peak frequency of $130 \mathrm{kHz}$ (Møhl \& Andersen 1973, Au et al. 1999, Villadsgaard et al. 2007) — a suitable frequency for automatic detection. They produce clicks almost continuously (Akamatsu et al. 2007, Linnenschmidt et al. 2013), and few other sounds in 

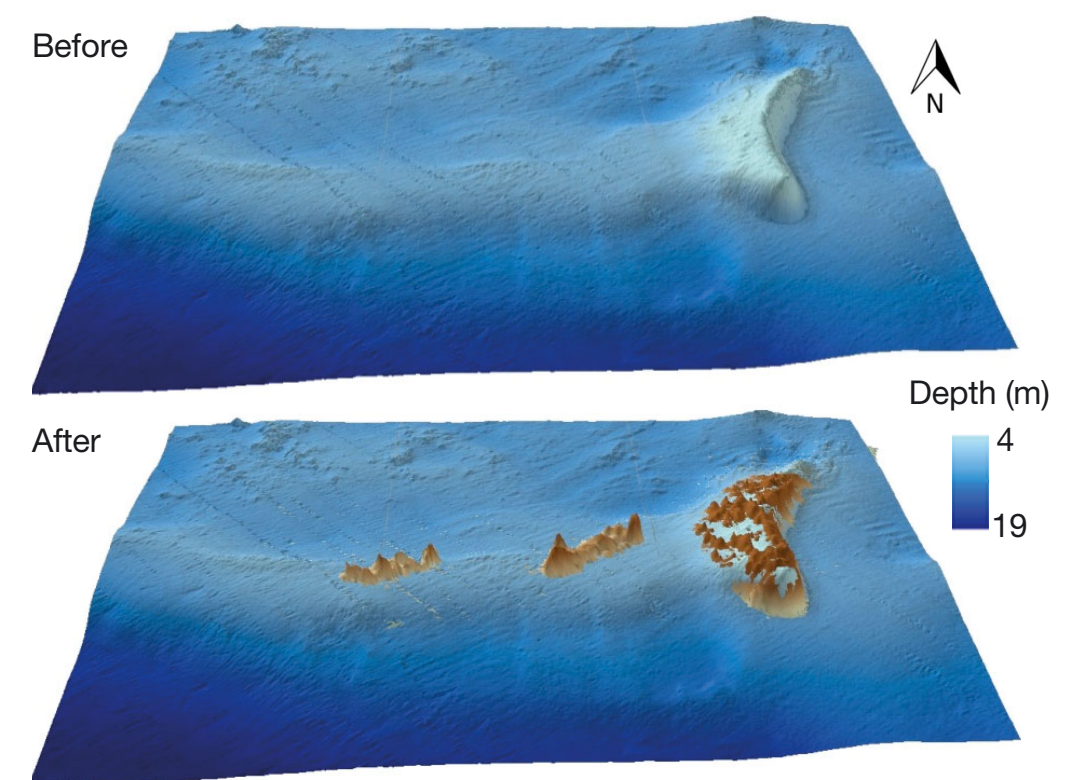

Fig. 2. Bathymetric maps showing the contours of the reef at Læsø Trindel before $(4.0-18.0 \mathrm{~m})$ and after $(1.5-18.0 \mathrm{~m})$ reconstruction. The brown markings denote the re-established areas. Data from Leth \& Al-Hamdani (2012) and The Danish Nature Agency (before and after reconstruction, respectively)

the ocean can be mistaken for porpoise clicks. Accordingly, static acoustic data loggers have proven to be a reliable proxy of porpoise occurrence in many studies, several of which address changes in occurrence due to changes in the environment. For example, some studies have used acoustic monitoring to assess the impact of construction and operation of offshore wind farms (Carstensen et al. 2006, Brandt et al. 2011, Scheidat et al. 2011).

\section{MATERIALS AND METHODS}

In addition to the study site at Læsø Trindel, a nearby intact reef area (Per Nilen) was selected as a reference station. This reef is located approximately $10 \mathrm{~km}$ southwest of Læsø Trindel (Fig. 1) and is a well-developed stony reef with a vertical distribution of 6.0 to $11.5 \mathrm{~m}$ water depth. It is composed of stones (10 to $60 \mathrm{~cm}$ in diameter) with larger boulders on top $(>60 \mathrm{~cm})$, which create cavernous areas surrounded by gravel and sand. Per Nilen is located in more sheltered waters than Læsø Trindel, closer to both Læsø Island and a long, very shallow sandbar to the west (Fig. 1). Per Nilen has not been mapped in detail, but is considerably smaller than Læsø Trindel. The reef is covered by multilayered macroalgal vegetation with relatively high biomass (Dahl \& Lundsteen 2010).
Tidal amplitudes are very small $( \pm 0.2 \mathrm{~m})$ around Læsø Trindel, and water levels are primarily determined by meteorological factors.

\section{Monitoring of harbour porpoises}

The acoustic activity of harbour porpoises in both areas was recorded through passive acoustic monitoring (PAM) using timing porpoise detectors (T-PODs, Chelonia). The T-POD is an acoustic data logger used for static PAM of porpoises and other odontocetes. It consists of a hydrophone, an amplifier, 2 band-pass filters, and a digital timing and logging system that stores information on the time of occurrence and duration of possible porpoise clicks. A detection is recorded when energy in the target filter (A) exceeds energy in the reference filter (B) by a set ratio. As porpoise clicks contain virtually no energy below $100 \mathrm{kHz}$, these clicks can be reliably discriminated from those of other odontocete, as well as most other transient sounds, with appropriate filter settings. The T-PODs used in this study were Version 3 and had the following settings: $\mathrm{A}$ filter $=130 \mathrm{kHz}$, short; $\mathrm{B}$ filter $=$ $90 \mathrm{kHz}$, long; ratio $\mathrm{A} / \mathrm{B}=5$; detection threshold $=6$; no scan limit; minimum click duration $=30 \mu \mathrm{s}$. See Kyhn et al. (2008) and Todd et al. (2009) for further details on operation and settings. Version 3 T-PODs have a maximum detection range of around $500 \mathrm{~m}$, although the probability of detection decreases quickly with increasing distance to the logger (Kyhn et al. 2012). The T-PODs used in the present study were calibrated to comparable sensitivity $125 \mathrm{~dB}$ rel. $1 \mu \mathrm{Pa}$ (peak-peak) $\pm 3 \mathrm{~dB}$ in November 2005 .

Two T-PODs were deployed at both stations: PODs no. 333 and 337 at Læsø Trindel and PODs no. 377 and 339 at the reference station. The T-POD pairs were deployed only a few metres apart as redundancies, to reduce the risk of data loss if 1 instrument malfunctioned. T-PODs were deployed at 10 to $11 \mathrm{~m}$ depth approximately $1 \mathrm{~m}$ above the sea floor. The system was attached to iron anchors without surface markers. The same T-POD pairs were deployed at Læsø Trindel and at the reference station in all years. Deployment time for individual units ranged from 33 to $75 \mathrm{~d}$ between June and August each year from 2006 to 2012. T-PODs were recovered by divers at the end of each deployment period. 
The recorded data were downloaded to a computer, analysed by the associated software (T-POD v. 8.17) and exported for statistical analysis. The T-POD software groups the recorded clicks into trains of clicks and assigns a confidence class to each train, based on the likelihood that the train originated from a porpoise. The details of this classification are not provided by the manufacturer, although they are based primarily on analysis of inter-click intervals (ICIs). Click trains are classified into CetHi (highprobability cetacean trains), CetLo (low-probability cetacean trains), doubtful trains, very doubtful trains and boat sonar trains. Only the 2 groups with trains most likely to have originated from porpoises (CetHi and CetLo) were used for further analysis, in accordance with previous studies (Carstensen et al. 2006, Scheidat et al. 2011, Kyhn et al. 2012)

Following the convention established by Carstensen et al. (2006), 3 indicators of harbour porpoise activity were used: (1) porpoise positive minutes (PPM) per day, which is a count of the number of minutes per day with acoustic activity; (2) durations of acoustic encounters, where an acoustic encounter is defined as a series of successive porpoise click trains where silent periods (pauses) between trains are less than $10 \mathrm{~min}$, interpreted as a group of click trains likely to be from the same porpoise or group of porpoises; and (3) waiting time between acoustic encounters, which is the duration of the silent periods between sequential acoustic encounters. By definition, the waiting time has a lower limit of $10 \mathrm{~min}$. Additionally, diel activity patterns were analysed using the midpoint times of each acoustic encounter. Only days with full 24 -h coverage were included in the analysis, i.e. the first and last incomplete days of a recording period were discarded.

\section{Statistical analyses}

Statistical analyses were carried out using the SPSS software package (v. 19.0). All of the exported time series were analysed using a full factorial generalised linear model with year and location as the main fixed factors. Season was not included in the statistical model as all recording periods took place between the start of June and mid-August, and could thus be considered to all represent 1 season (summer).

Assessed dependent variables (PPM, encounter duration and waiting time) were analysed for the presence of autocorrelation separately for each deployment year and site. PPM was generally auto- correlated with one-day lag time $(t-1)$ at both study sites. Encounter duration and waiting time, in contrast, showed little autocorrelation, and these 2 variables were therefore not corrected for autocorrelation in the main analyses. PPM was expressed as a percentage (number of minutes per day with activity divided by total number of minutes per day), arcsine transformed and analysed in a full factorial model with year and location as fixed factors. To correct for autocorrelation, the variable $\mathrm{PPM}_{t-1}$ (PPM recorded during the previous day) was incorporated into the model as a covariate. The analysis of PPM was, however, carried out on rank-transformed data to obtain homogeneity of error variance.

Homogeneity of error variance could not be obtained for either encounter duration or waiting time, even after log- or rank-transformation of data. Hence, the nonparametric Kruskal-Wallis test and associated post-hoc test, corrected for multiple comparisons, were applied to each of the 2 study sites separately.

Diel variation in encounter rate was analysed using circular statistics (Batschelet 1981). Encounter midpoint times were transformed to angles in a circle. This provided a vector angle, $\theta$, representing the time of day when activity was most concentrated, and a vector length, $r$, expressing the degree of concentration. The length of $r$ varies between 0 and 1, with 0 representing even dispersion around the entire circle (and thus also a 24-h period) and 1 representing the maximum possible concentration. The circular transformation also allowed us to test for differences in mean angle among samples (MardiaWatson-Wheeler test), i.e. testing a null hypothesis that 2 samples of porpoise acoustic encounters are concentrated around the same time of day.

The 2 T-PODs deployed at each station for redundancy reasons cannot serve as independent replicates as they were separated by only a few metres and hence exposed to almost identical porpoise sounds. Only data from the T-POD in each pair with the longest continuous recording series over the entire study period were used in the full analysis (POD no. 333 for Læsø Trindel and POD no. 337 for the reference station). T-PODs are known to differ in sensitivity (Kyhn et al. 2008, 2012). We therefore tested the performance of each T-POD against that of its partner in a 2-way ANOVA, which included TPOD serial number and Year as fixed factors and ranked PPM as a dependent variable. Neither T-POD serial number nor the interaction term between $\mathrm{T}$ POD serial number and Year were found to be significant factors (Læesø Trindel $p \geq 0.334$, reference station $\mathrm{p} \geq 0.457$ ). This means that the recorded data are 
comparable across T-PODs and years, and that no bias is introduced into the data by excluding data from the redundant T-PODs.

\section{RESULTS}

\section{Reef attendance}

A pronounced change in the pattern of porpoise activity at both stations coincided with the restoration of the reef in 2008 (Table 1, Fig. 3). The significant interaction between Year and Location (Table 1) demonstrates that development of PPM across years differed between the 2 stations. At Læsø Trindel, PPM per day increased from 2008 and onwards, with a minor drop in 2012, whereas PPM per day generally decreased at the reference station (Fig. 3). A sta-

Table 1. Summary statistics from the full factorial generalised linear model analysis on the effect of year (20062012) and location (Læsø Trindel and reference station) on rank-transformed porpoise positive minutes (PPM). Owing to the presence of autocorrelation (see 'Materials and methods'), PPM recorded during the previous day $\left(\mathrm{PPM}_{t-1}\right)$ was included as a covariate in the model

\begin{tabular}{|lrrr|}
\hline Source of variation & df & \multicolumn{1}{c|}{$F$} & \multicolumn{1}{c|}{$\mathrm{p}$} \\
\hline Year & 6 & 2.769 & 0.0110 \\
Location & 1 & 50.355 & $<0.0005$ \\
Year $\times$ Location & 6 & 12.120 & $<0.0005$ \\
Covariate $(t-1)$ & 1 & 68.560 & $<0.0005$ \\
\hline
\end{tabular}

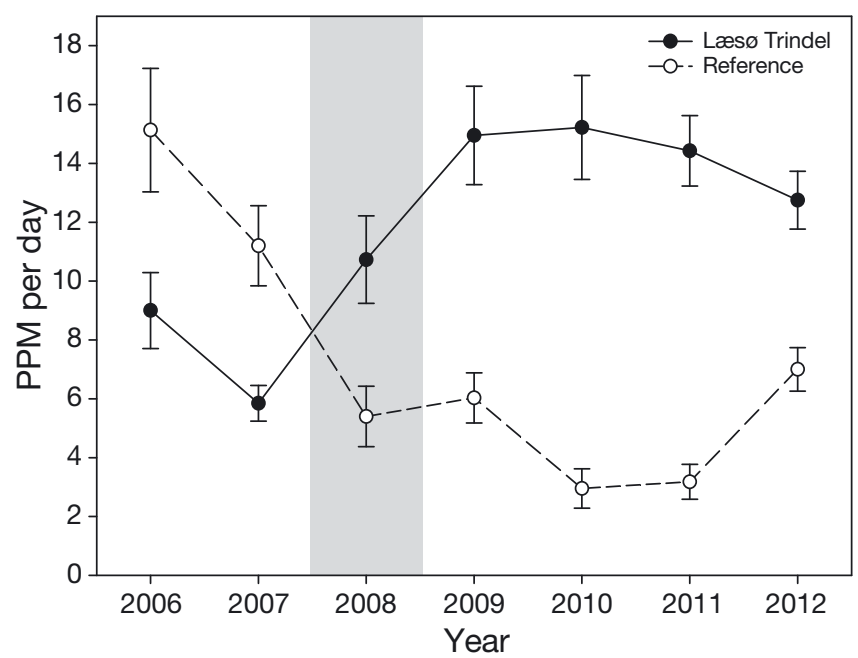

Fig. 3. Mean porpoise positive minutes (PPM) per day $( \pm \mathrm{SE})$ at Læsø Trindel stony reef and at the reference station as a function of year. The grey area indicates the year of reef reconstruction (2008) tistical significant effect of the covariate (t-1) (Table 1) demonstrates that PPM on any given day depends on the PPM value of the previous day.

At Læsø Trindel, the encounter duration increased in general over the study period (Fig. 4; KruskalWallis test, $\left.\chi_{6}^{2}=33.222, \mathrm{p}<0.0005\right)$. The mean encounter duration did not change from 2008 to 2012 (post-hoc tests, $\mathrm{p} \geq 0.484$ ) at Læsø Trindel. However, the post reconstruction years 2009 to 2011 had significantly longer mean encounter durations than the pre-reconstruction year 2007 (post-hoc tests, $\mathrm{p} \leq 0.011$ ), with encounter durations for 2009 to 2010 also being significantly higher than those in 2006 (post-hoc tests, $\mathrm{p} \leq 0.017$ ) (2011 was close to significance, post-hoc test, $\mathrm{p}=0.057$ ). In contrast, encounter duration did not change over the study period at the reference station (Fig. 4; Kruskal-Wallis test, $\chi_{6}^{2}=$ 1.753, $\mathrm{p}=0.472$ ).

Waiting times between acoustic encounters declined at Læsø Trindel during the study period (Fig. 5; Kruskal-Wallis test, $\chi^{2}{ }_{6}=73.004, \mathrm{p}<0.0005$ ). Waiting times in 2009 to 2012 were significantly shorter than in 2007 (post-hoc tests, p < 0.0005). This not only indicates that the increased activity in terms of PPM seen at Læsø Trindel after 2008 (Fig. 3) was the result of longer encounter durations, but also that encounters occurred more frequently. The opposite was evident at the reference station, where waiting times increased in general during the study period, with the longest waiting times recorded in 2009 and 2010 (Fig. 5; Kruskal-Wallis test, $\chi^{2}{ }_{6}=114.148$, p < 0.0005). This means that encounters were of the same mean duration (Fig. 4), but occurred less frequently over the study period.

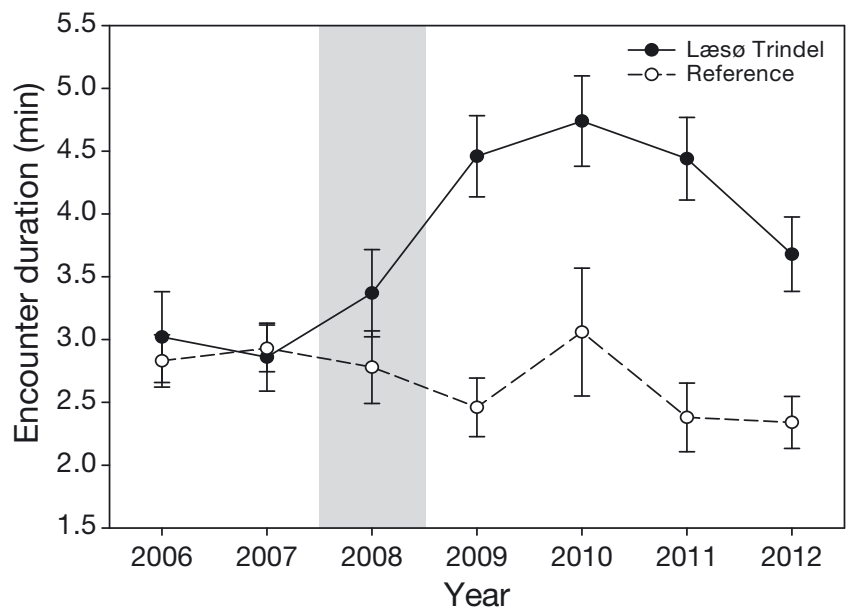

Fig. 4. Mean encounter duration per day in minutes $( \pm \mathrm{SE})$ at Læsø Trindel stony reef and at the reference site by year. The grey area indicates the year of reef reconstruction (2008) 


\section{Diel activity patterns}

Harbour porpoise detections did not occur consistently around the clock at Læsø Trindel throughout the whole study period (Fig. 6). No significant diel

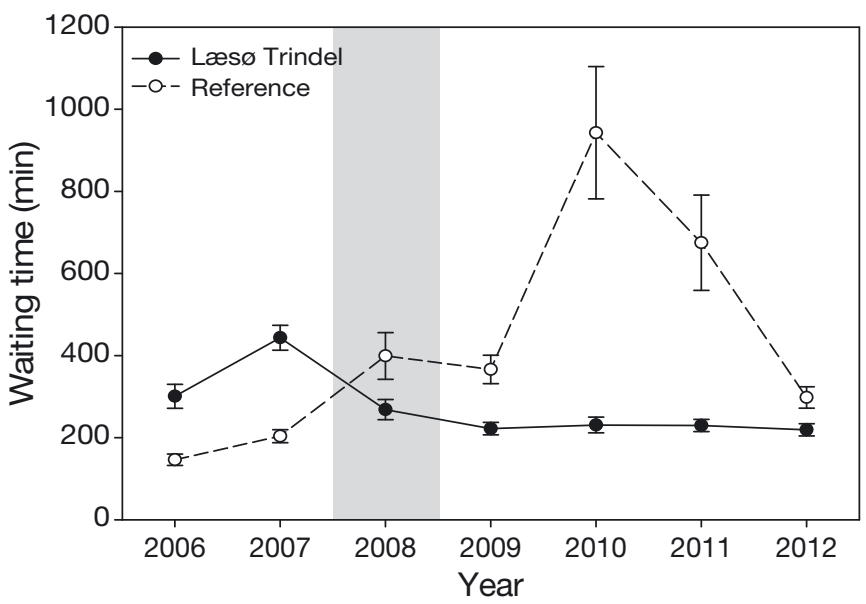

Fig. 5. Mean waiting times between acoustic encounters in minutes $( \pm$ SE) at Læsø Trindel stony reef and at the reference station by year. The grey area indicates the year of reef reconstruction (2008) pattern was found in $2006(\mathrm{p}=0.355)$, but in 2007, the year preceding the reconstruction, a weak but significant peak in activity during late night/early morning was seen $(\theta=04: 45 \mathrm{~h}, r=0.17, \mathrm{p}=0.001)$. During the years 2008 to 2011 the porpoises' nocturnal activity became increasingly pronounced, as illustrated by the increasing vector lengths $(r)$ centred between 00:00 and 02:00 h local time (Fig. 6). High nocturnal activity was still seen in 2012, although there were relatively more detections during the day, especially in the late afternoon hours, than in the previous postreconstruction years. The activity level during hours of daylight remained largely unchanged at 0.1-0.2 encounters per day during the years 2006-2011 at Læsø Trindel, also suggesting that the increased activity observed here (Figs. $3 \& 4$ ) was concentrated at night. The reference station differed from Læsø Trindel by a distinct diurnal peak in activity centred around 12:00-14:00 h (Fig. 6), except in 2008 when a low concentration of activity was centred around 18:03 h (Fig. 6). Mean time of occurrence differed significantly between the 2 stations for all years when tested pairwise (two-sample Mardia-WatsonWheeler tests, $\mathrm{W} \geq 22.187, \mathrm{p}<0.0005$ ).
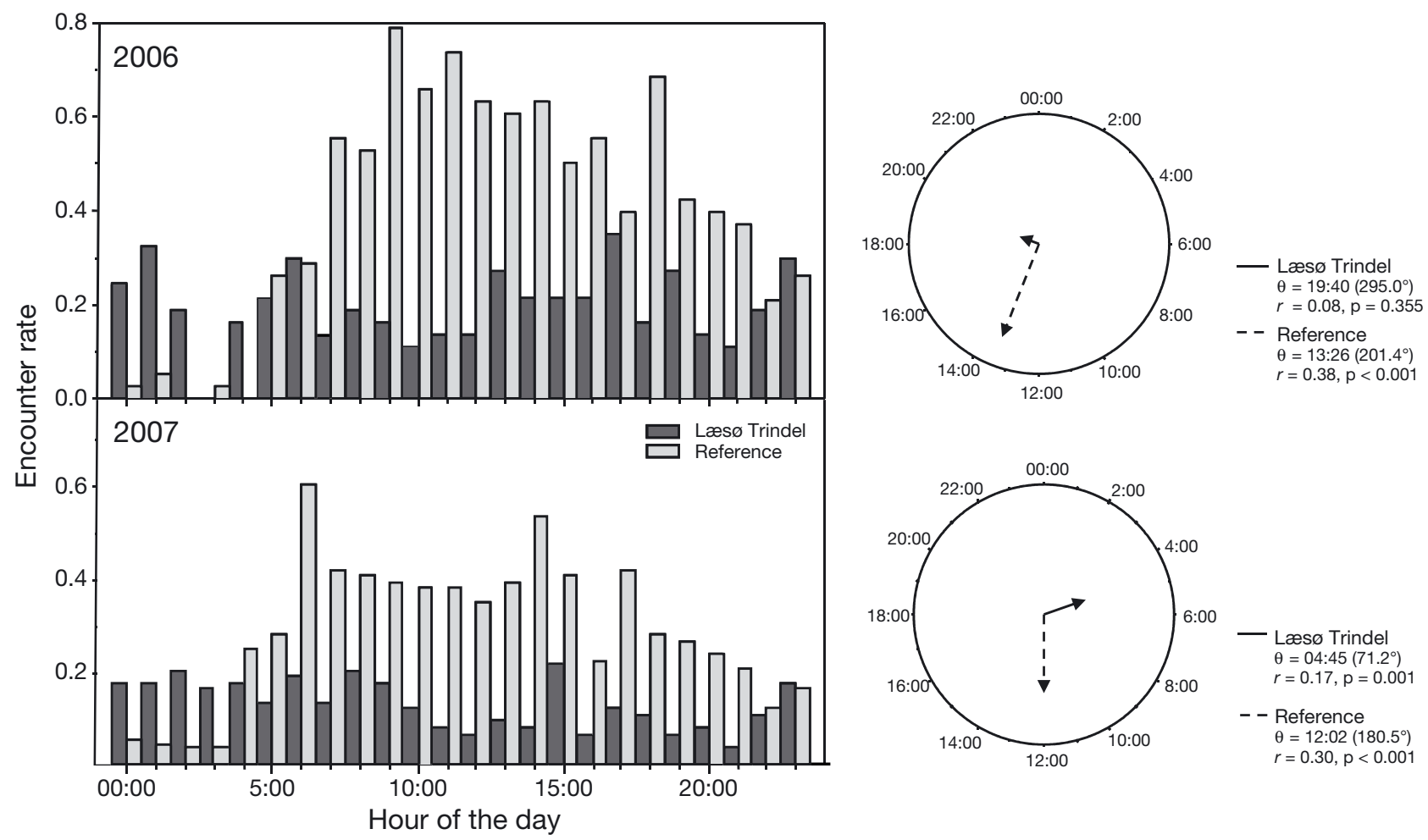

Fig. 6. (Above and facing page.) Mean number of porpoise encounters by hour of the day (encounter rate; left panels), and circular summary statistics on the central tendency in diel activity providing vector length and direction (right panels), for each year of study. Vector direction $(\theta)$ is given in hours of the day $(24 \mathrm{~h}$, local summertime UTC+2); $r$ and $p$ denote vector length and associated statistical significance, respectively. Depicted vector lengths have been doubled in relation to a unit circle 

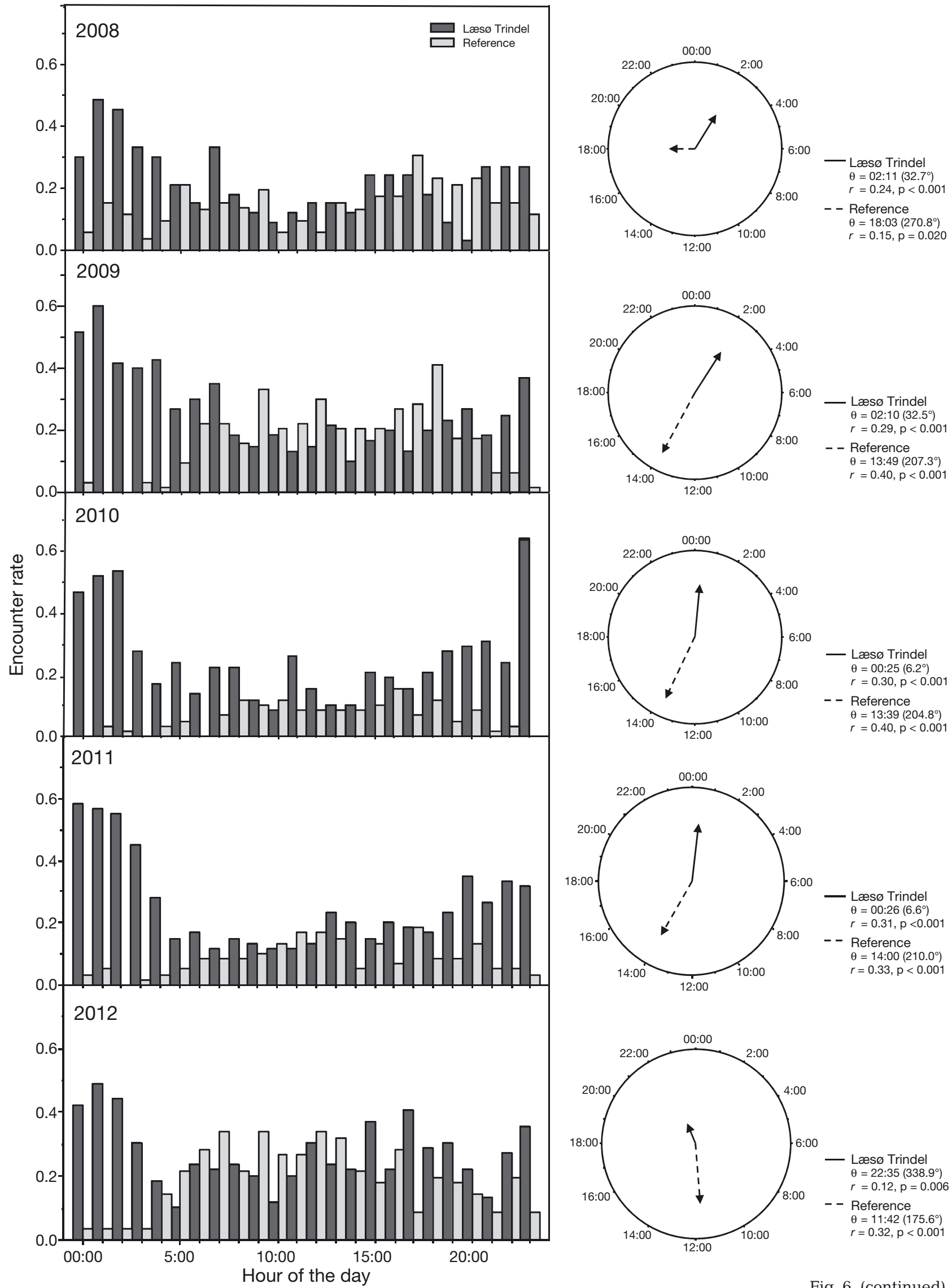

Fig. 6. (continued) 
Dividing the encounter duration into day and night demonstrated that the daytime levels at Læsø Trindel were constant at around 2.0 to $3.0 \mathrm{~min}$ throughout the study period (Fig.7; Kruskal-Wallis test, $\chi_{6}^{2}=$ 1.842, $\mathrm{p}=0.934$ ), whereas nocturnal encounter durations increased during the study period (KruskalWallis test, $\left.\chi_{6}^{2}=17.983, \mathrm{p}=0.006\right)$. Nocturnal mean encounter durations were around 4.0-4.5 $\mathrm{min}$ in the years 2006-2008, increasing to about 5.5-7.0 min in 2009-2012. At the reference station, no statistical significant difference was found in encounter durations over the study period (Fig. 7), for either day (KruskalWallis test, $\chi_{6}^{2}=6.274, \mathrm{p}=0.393$ ) or night (KruskalWallis test, $\chi_{6}^{2}=11.030, \mathrm{p}=0.087$ ).

\section{DISCUSSION}

Pronounced changes in the acoustic activity of porpoises were observed following the reconstruction of the reef at Læsø Trindel during the summer of 2008. Porpoises were recorded more often during and after the reconstruction than before, with the change most pronounced at night. These changes may reflect an increased number of porpoises at the reef, an increase in the time individual porpoises spent at the reef, changing echolocation behaviour, or a combination of these. In parallel to this, there was a general decrease in activity at the reference station, with the greatest concentrations in the daylight hours. Thus, the rebuilding of the Læsø Trindel reef seems to have had an immediate positive effect on porpoises in the area. Furthermore, it appears that porpoises used the 2 areas differently, with their main period of activity at the 2 stations being at opposing times of day.

The increased porpoise activity at Læsø Trindel could be explained by an increase in prey abundance. So far there is no quantitative data on fish abundance available from Læsø Trindel after the restoration to support this. However, annual surveys conducted at Læsø Trindel as part of the national reef monitoring programme targeting macroalgal vegetation and hard-bottom fauna have taken place since 1991. These have shown that the biological colonisation was notably underway on the new boulders in 2010 (Dahl \& Lundsteen 2010). Also, divers from the programme have reported increased numbers of wrasse, saithe Pollachius virens, cod and even sandeel (Family: Ammodytidae) on Læsø Trindel since the establishment of the new reef structures (K. Dahl unpubl. data). However, quantitative assessments of fish abundance are not possible from diving surveys. Similarly, it is also not known if harbour porpoises are

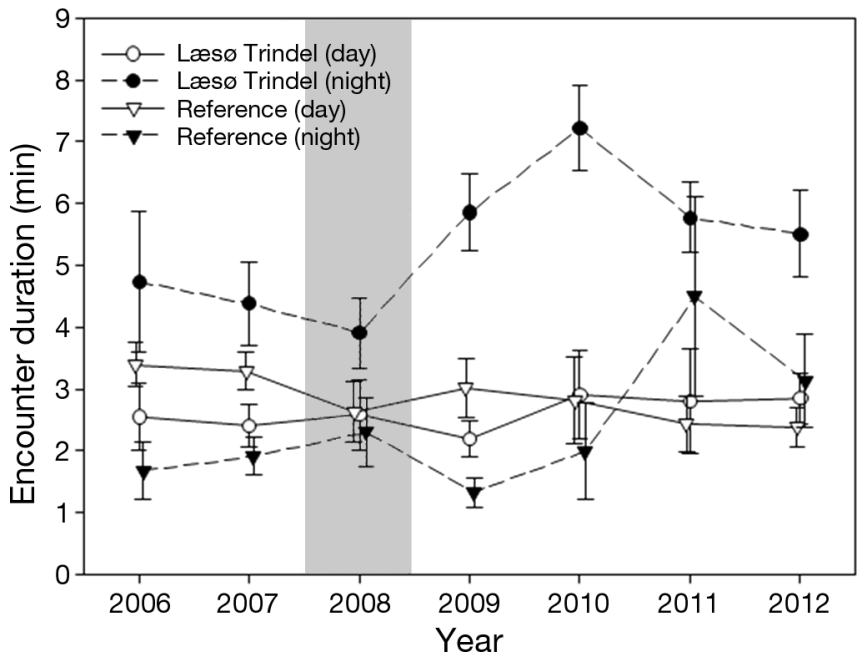

Fig. 7. Mean encounter duration in minutes $( \pm \mathrm{SE})$ were calculated for a $6 \mathrm{~h}$ period around solar noon (10:00-16:00 h) and for $6 \mathrm{~h}$ around solar midnight (22:00-04:00 h) at Læsø Trindel and at the reference station by year. Data points have been offset on the $x$-axis to improve readability. Kruskal-Wallis tests show no difference between years except for Læsø Trindel (night) (see 'Results'). The grey area indicates the year of reef reconstruction (2008)

targeting the reported species on the reef. Stomach content analyses of harbour porpoises from the population inhabiting Skagerrak and the Kattegat have shown that herring, Atlantic cod, gobies and whiting are among the most important prey species (Aarefjord et al. 1995, Börjesson et al. 2003). Still, many other fish species, such as sandeel, sprat Sprattus sprattus, saithe, etc., were also found in lower numbers, showing that porpoises are preying on a large variety of species (Aarefjord et al. 1995, Börjesson et al. 2003, Sveegaard et al. 2012a). Following this, it seems likely that the observed fish species at Læsø Trindel would be of interest to porpoises in the area.

Studies on other artificial reefs have shown that they are quickly colonised by marine flora and fauna. Russell (1975) observed fish within a few days of an artificial reef being created from rubber tires, with fish populations becoming established within 3 mo. Stone et al. (1979) also observed that fish were making use of the shelter provided by another artificial reef as soon as it was constructed, and that fish biomass increased over the first 7 mo. Bohnsack \& Sutherland (1985) critically examined the artificial-reef literature and concluded that such reefs have a great potential for habitat enhancement as fish can colonise reefs very rapidly, and numerous studies have proven them to be very effective in enhancing fish resources. Therefore, it seems likely that the new boulders at Læsø Trindel almost instantly attracted fish from the 
area immediately surrounding the new reef. It is also likely that fish abundance increased further at Læsø Trindel in the years following reconstruction. Additionally, studies have also shown that predators are attracted to such reef environments where prey species aggregate (Logan Kock 1982, Leitão et al. 2008). Accordingly, this would explain the increase in porpoise activity seen in 2008 and the following years.

During the baseline studies conducted on the reef in 2007, acoustic tagging of juvenile cod showed a pronounced diel pattern of movement in the summer months. The cod moved into the reef at sunset and returned to deeper waters at sunrise (Dahl et al. 2009). Similarly, herring have been reported to ascend at night, following the zooplankton they feed on, as well as moving into deeper waters during the day (Cardinale 2003, Onsrud et al. 2004). These findings offer a plausible explanation as to why harbour porpoises were predominantly recorded at night at Læsø Trindel. Thus, it seems likely that the porpoises in the northern Kattegat follow the activity and movement patterns of juvenile cods at Læsø Trindel, and perhaps also other migrating fish species.

In contrast to the distinct nocturnal peak in activity at Læsø Trindel reef, porpoises rarely visited the reference area during nighttime, but were mostly active there during daylight hours. The location of the 2 reefs and their surrounding environments may offer an explanation to this difference. The reef at Læsø Trindel is situated on the edge of a slope to deeper waters, whereas the reference station is located on a relatively flat plateau (Fig. 1). Hence, the diel migratory pattern of fish between deep and shallow water, which porpoises may follow as described above, may be more pronounced closer to the slope (i.e. Læsø Trindel).

Our results are in line with those of Todd et al. (2009) who also found a pronounced diel pattern in harbour porpoise echolocation activity around a North Sea offshore gas installation. The acoustic activity was greater at night than during the day, and the number of click trains with minimum ICIs less than $10 \mathrm{~ms}$ increased at night. Short ICIs are a putative indicator of feeding behaviour (Carlström 2005, Verfuß et al. 2009), but no definite link between feeding behaviour and acoustic recordings on T-PODs has yet been established. In other words, additional, independent information is required to conclude that a high proportion of low ICI-trains can be reliably used as a proxy for foraging behaviour. This independent information could be in the form of, for example, video recordings or simultaneous recordings from an instrument on the porpoise.
The slight drop in activity that was observed in 2012 (Figs. 3 \& 4) could be attributed to natural variation or it could be a downward trend. However, it is not possible to differentiate between these 2 possibilities without additional data from coming years. Furthermore, higher levels of activity were seen during the daylight hours at Læsø Trindel in 2012 than in the previous years (Fig. 6), so it is also possible that a new diel pattern is emerging, with the reef attracting more porpoises to the area during the daytime, possibly due to continuous development of the ecology on the new reef.

In conclusion, harbour porpoises were recorded more often at Læsø Trindel reef after the reconstruction, particularly at night, possibly due to increased feeding activity. The occurrence and behaviour of harbour porpoises at a particular site is probably primarily determined by prey abundance. Factors affecting local prey abundance may, in turn, be very habitat specific, explaining the large differences found between the 2 study sites.

This study showed that a positive effect of reef reconstruction could be observed immediately at the level of a top predator, the harbour porpoise. This indicates that the reef restoration had an instant, profound and presumably positive effect on the ecosystem at Læsø Trindel. This result is encouraging because it adds support to the belief that stony reefs are very important to the marine ecosystem in the Kattegat and shows that immediate positive ecosystem effects can be achieved through restoration projects.

Acknowledgements. The Blue Reef project was funded by EU LIFE and the Danish Nature Agency. We sincerely thank L. Renvald and L. O. Mortensen for excellent assistance with deployment and recovery of the T-PODs, and C. Göke for preparation of the maps. We thank 4 anonymous reviewers as well as S. Sveegaard, L. A. Kyhn, N. P. Huffeldt and A. Wright for comments to earlier versions of this manuscript.

\section{LITERATURE CITED}

Aarefjord H, Bjørge A, Kinze CC, Lindsted I (1995) Diet of the harbour porpoise Phocoena phocoena in Scandinavian waters. Rep Int Whal Comm Spec Issue 16:211-222

Akamatsu T, Teilmann J, Miller LA, Tougaard J and others (2007) Comparison of echolocation behaviour between coastal and riverine porpoises. Deep-Sea Res Part II 54: 290-297

Andrulewicz E, Kruk-Dowgiallo L, Osowiecki A (2004) Phytobenthos and macrozoobenthos of the Slupsk Bank stony reefs, Baltic Sea. Hydrobiologia 514:163-170

Au WWL, Kastelein RA, Rippe T, Schooneman NM (1999) Transmission beam pattern and echolocation signals of a harbor porpoise (Phocoena phocoena). J Acoust Soc Am 106:3699-3705 
Batschelet E (1981) Circular statistics in biology. Academic Press, London

Bohnsack JA, Sutherland DL (1985) Artificial reef research: a review with recommendations for future priorities. Bull Mar Sci 37:11-39

Börjesson P, Berggren P, Ganning B (2003) Diet of the harbour porpoise in the Kattegat and Skagerrak seas: accounting for individual variation and sample size. Mar Mamm Sci 19:38-58

> Brandt MJ, Diederichs A, Betke K, Nehls G (2011) Responses of harbour porpoises to pile driving at the Horns Rev II offshore wind farm in the Danish North Sea. Mar Ecol Prog Ser 421:205-216

> Cardinale M, Michele C, Arrhenius F, Håkansson N (2003) Diel spatial distribution and feeding activity of herring (Clupea harengus) and sprat (Sprattus sprattus) in the Baltic Sea. Aquat Living Resour 16:283-292

> Carlström J (2005) Diel variation in echolocation behavior of wild harbor porpoises. Mar Mamm Sci 21:1-12

> Carstensen J, Henriksen OD, Teilmann J (2006) Impacts of offshore wind farm construction on harbour porpoises: acoustic monitoring of echolocation activity using porpoise detectors (T-PODs). Mar Ecol Prog Ser 321:295-308

Charbonnel E, Serre C, Ruitton S, Harmelin JG, Jensen A (2002) Effects of increased habitat complexity on fish assemblages associated with large artificial reef units (French Mediterranean coast). ICES J Mar Sci 59:S208-S213

Dahl K, Lundsteen S (2010) Blue Reef: status for den biologiske indvandring på Læsø Trindels nye rev i 2010. Tech Rep No. 262, National Environmental Research Institute, Roskilde, http://www2.dmu.dk/Pub/AR262.pdf

Dahl K, Stenberg C, Lundsteen S, Støttrup J, Dolmer P, Tendal OS (2009) Ecology at Læsø Trindel: a reef impacted by the extraction of boulders. Tech Rep No. 757, National Environmental Research Institute, Roskilde, http:// www2.dmu.dk/Pub/FR757.pdf

Demartini EE, Roberts DA (1990) Effects of giant kelp (Macrocystis) on the density and abundance of fishes in a cobble-bottom kelp forest. Bull Mar Sci 46:287-300

Fager EW (1971) Pattern in the development of a marine community. Limnol Oceanogr 16:241-253

Giansante C, Fatigati M, Ciarrocchi F, Milillo GS, Onori L, Ferri N (2010) Monitoring of ichthyic fauna in artificial reefs along the Adriatic coast of the Abruzzi region of Italy. Vet Ital 46:365-374

> Goodwin L (2008) Diurnal and tidal variations in habitat use of the harbour porpoise (Phocoena phocoena) in Southwest Britain. Aquat Mamm 34:44-53

Hammond PS, Berggren P, Benke H, Borchers DL and others (2002) Abundance of harbour porpoise and other cetaceans in the North Sea and adjacent waters. J Appl Ecol 39:361-376

> Johnston DW, Westgate AJ, Read AJ (2005) Effects of finescale oceanographic features on the distribution and movements of harbour porpoises Phocoena phocoena in the Bay of Fundy. Mar Ecol Prog Ser 295:279-293

Koopman HN (1998) Topographical distribution of the blubber of harbor porpoises (Phocoena phocoena). J Mammal 79:260-270

Kyhn LA, Tougaard J, Teilmann J, Wahlberg M, Jorgensen PB, Bech NI (2008) Harbour porpoise (Phocoena phocoena) static acoustic monitoring: laboratory detection thresholds of T-PODs are reflected in field sensitivity. J Mar Biol Assoc UK 88:1085-1091

Kyhn LA, Tougaard J, Thomas L, Duve LR and others (2012) From echolocation clicks to animal density-acoustic sampling of harbour porpoises with static dataloggers. J Acoust Soc Am 131:550-560

Leitão F, Santos MN, Erzini M, Monteiro CC (2008) The effect of predation on artificial reef juvenile demersal fish species. Mar Biol 153:1233-1244

Leth JO, Al-Hamdani Z (2012) Broad scale habitat mapping of the Natura 2000 site 168: Læsø Trindel and Tønneberg Banke, Kattegat, Denmark. GEUS Report 2012/15. Geological Survey of Denmark and Greenland, Copenhagen

Linnenschmidt M, Teilmann J, Akamatsu T, Dietz R, Miller LA (2013) Biosonar, dive and foraging activity of satellite tracked harbour porpoises (Phocoena phocoena). Mar Mamm Sci 29:E77-E97

Logan Kock RK (1982) Patterns of abundance variation in reef fishes near an artificial reef at Guam. Environ Biol Fishes 7:121-136

> Møhl B, Andersen S (1973) Echolocation: high-frequency component in the click of the harbor porpoise (Phocoena ph. L.). J Acoust Soc Am 54:1368-1372

$>$ Moreno CA, Jara HF (1984) Ecological studies on fish fauna associated with Macrocystis pyrifera belts in the south of Fueguian Islands, Chile. Mar Ecol Prog Ser 15:99-107

$>$ Ojeda FP, Dearborn JH (1989) Community structure of macroinvertebrates inhabiting the rocky subtidal zone in the Gulf of Maine: seasonal and bathymetric distribution. Mar Ecol Prog Ser 57:147-161

> Onsrud MSR, Kaartvedt S, Røstad A, Klevjer TA (2004) Vertical distribution and feeding patterns in fish foraging on the krill Meganyctiphanes norvegica. ICES J Mar Sci 61: 1278-1290

> Pierpoint C (2008) Harbour porpoise (Phocoena phocoena) foraging strategy at a high energy, near-shore site in south-west Wales, UK. J Mar Biol Assoc UK 88:1167-1173

Relini G, Relini M, Torchia G, Palandri G (2002) Ten years of censuses of fish fauna on the Loano artificial reef. ICES J Mar Sci 59:S132-S137

Russell BC (1975) The development and dynamics of a small artificial reef community. Helgol Wiss Meeresunters 27: 298-312

Scheidat M, Tougaard J, Brasseur S, Carstensen J, Petel TvP, Teilmann J, Reijnders P (2011) Harbour porpoises (Phocoena phocoena) and wind farms: a case study in the Dutch North Sea. Environ Res Lett 6, doi:10.1088/17489326/6/2/025102

Stone RB, Pratt HL, Parker RO Jr., Davis GE (1979) A comparison of fish populations on an artificial and natural reef in the Florida Keys. Mar Fish Rev 41:1-11

Sveegaard S, Andreasen H, Mouritsen KN, Jeppesen JP, Teilmann J, Kinze CC (2012a) Correlation between the seasonal distribution of harbour porpoises and their prey in the Sound, Baltic Sea. Mar Biol 159:1029-1037

> Sveegaard S, Nabe-Niesen J, Stæhr KJ, Jensen TF, Mouritsen KN, Teilmann J (2012b) Spatial interactions between marine predators and their prey: herring abundance as a driver for the distributions of mackerel and harbour porpoise. Mar Ecol Prog Ser 468:245-253

Todd VLG, Pearse WD, Tregenza NC, Lepper PA, Todd IB (2009) Diel echolocation activity of harbour porpoises (Phocoena phocoena) around North Sea offshore gas installations. ICES J Mar Sci 66:734-745

> Verfuß UK, Miller LA, Pilz RKD, Schnizler HU (2009) Echolocation by two foraging harbour porpoises (Phocoena phocoena). J Exp Biol 212:823-834

Villadsgaard A, Wahlberg M, Tougaard J (2007) Echolocation signals of wild harbour porpoises, Phocoena phocoena. J Exp Biol 210:56-64 